\title{
El coro en los fragmentos trágicos de Esquilo
}

\section{The chorus in Aeschylus' tragic fragments}

Miriam Librán Moreno

Universidad de Extremadura, España

mlibmor@unex.es

iD http://orcid.org/0000-0003-2632-8947

\section{Resumen:}

Análisis de la identidad, función y uso del coro en las tragedias fragmentarias de Esquilo.

Palabras clave: Esquilo, Tragedia fragmentaria, Coro.

\section{Abstract:}

A study of the identity, function, and dramatical uses of the chorus in Aeschylus' tragic fragments.

KEYWORDS: Aeschylus, Tragic fragments, Chorus.

\section{El coro en las tragedias de Esquilo}

Aristóteles afirmaba que el coro debía funcionar como uno más de los actores del drama, que había de formar parte del conjunto y que tenía que contribuir al desarrollo de la acción dramática (Poética

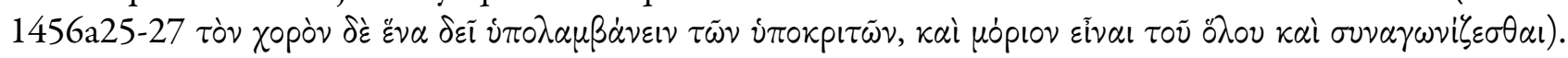
Tal ocurre con los coros de seis de las siete tragedias conservadas (Persas, Siete contra Tebas, Suplicantes, Agamenón, Coéforos y Euménides), pero habida cuenta de que Esquilo compuso en torno a 90 obras (Lucas de Dios, 2008, pp. 10-11), tal coincidencia podría deberse a un error estadístico. Así pues, se impone revisar si esta impresión, tan repetida en todos los manuales, se ve corroborada o negada por los datos deducibles de los fragmentos trágicos.

El propósito de la presente contribución, por tanto, será una primera aproximación al análisis, en la medida en que el contexto lo permita, de la naturaleza, actuación y función del coro en los fragmentos trágicos de Esquilo. ${ }^{1}$ En realidad, los testimonios antiguos sobre los coros de Esquilo coinciden en afirmar dos cosas: Esquilo aumentó la proporción del diálogo en detrimento del coro con respecto a la tragedia primitiva (Aristóteles, Poética 1449a17-18) y la coreografía y vestimentas de este eran memorables (Aristófanes fr. 696 K.-A., Ateneo 1.21D).

\section{Trilogías y tetralogías conectadas míticamente}

En este apartado agruparé las tragedias por trilogías y tetralogías claramente conectadas por el argumento y la materia mítica a la que pertenecen. ${ }^{2}$ "Tetralogía" se refiere al conjunto de tres trilogías y un drama satírico conectados por argumento o mito, mientras que "trilogía" se refiere únicamente a las tres tragedias (Lucas de Dios, 2008, pp. 12-14).

\subsection{Licurgía. Esta tetralogía estaba formada por Edonos, Basárides, Jóvenes y el drama satírico Licurgo (Radt, 1985, p. 111; West, 1990, pp. 26-50).}


(a) Edonos ('Howvoí) (Radt, 1985, pp. 178-183; Lucas de Dios, 2008, pp. 299-311). Esta tragedia, en la que se inspiró parcialmente Bacantes de Eurípides, dramatizaba la oposición del rey tracio Licurgo a la introducción del culto de Dioniso en su reino (escolio a Aristófanes, Tesmoforiantes 135). El coro estaría formado por varones pertenecientes a la tribu tracia de los edonos, sobre los que reinaba Licurgo (cf. Sófocles, Antígona 955-956). Desconocemos la actitud que tendría dicho coro tracio ante Dioniso: el fr. 57 R., en boca del coro, describe con minuciosidad y aparente reverencia los ritos de Dioniso, que se asemejan a los de una de sus diosas nacionales, Cotito (West, 1990, p. 27), pero al mismo tiempo el fr. 7 de Licurgo de Nevio, que muy verosímilmente estaba inspirado en la obra homónima de Esquilo (Dodds, 1960², p. xxxiii), describe el daño causado por las bacantes a las cosechas de los agricultores, por lo que el retrato de estas mujeres no sería enteramente positivo. Es esperable que en la primera tragedia de la tetralogía la actitud del coro fuera ambigua: como súbditos de Licurgo apoyarían a su rey, pero tendrían una voz y opinión propias, como el coro de Agamenón, seguramente conscientes de la desmesura de Licurgo.

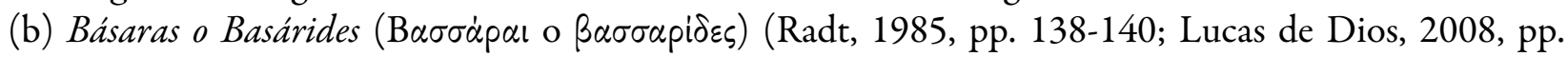
224-232). Esta tragedia dramatizaba la muerte de Orfeo a manos de mujeres tracias, que Esquilo identificaba con las basárides o adoradoras tracias de Dioniso (Ps. Eratóstenes, Catasterismos 24). La básara, que daba su nombre a las bacantes tracias, al parecer era un tipo de túnica larga y variopinta que identificaba a estas mujeres (Focio, Léxico $\beta$ 85). Según el testimonio de Ps. Eratóstenes, Dioniso, airado con la traición de Orfeo al abandonar su culto en favor del de Apolo, envió a sus servidoras las basárides a que castigaran a Orfeo. Las mujeres descuartizaron al infortunado músico y diseminaron sus miembros. Las Musas acudieron y recogieron los pedazos del cadáver, que enterraron en Libetra (Macedonia) (West, 1990, pp. 64-70). El coro de esta tragedia estaría formado, como declara el título, por bacantes tracias ataviadas con túnicas rituales (cf. fr. 59 R., de Edonos), de cuya vestimenta derivaría el título de la obra. No podemos dejar de recordar aquí la fama por los ropajes espectaculares de actores y coros que los testimonios antiguos atribuían a Esquilo (e.g. Vida de Esquilo 14, Ateneo $1.47 \mathrm{~K}$.). El propio coro no sería el encargado de dar muerte a Orfeo: al igual que en Bacantes de Eurípides, verosímilmente fue un grupo distinto de devotas de Dioniso, no las integrantes del coro, las que asesinarían a Orfeo fuera de escena (Jouan, 1992, p. 75).

Del testimonio de Ps. Eratóstenes podríamos asimismo deducir que pudo haber un segundo coro formado

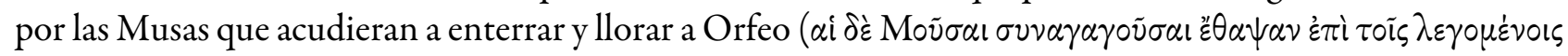
$\Lambda \varepsilon ı \dot{\eta} \theta$ poıs). En Eurípides, Reso 890-905, en la escena final de esta tragedia, ${ }^{3}$ una Musa acude a llorar y enterrar a Reso. Por otra parte, es posible que en Támiras de Sófocles las Musas aparecieran también como coro secundario (Lucas de Dios, 1983, pp. 111-112 n. 337). Un coro (principal) de Musas está atestiguado en Musas de Sófocles (frs. 407a-408 R.).

(c) Jóvenes (Neaviokol) (Radt, 1985, pp. 259-261; Lucas de Dios, 2008, pp. 453-457). Aunque se han hecho muchas conjeturas al respecto, desconocemos totalmente el argumento de la obra, si bien podemos estar seguros de que trataría la introducción y aceptación de los ritos dionisíacos en Tracia, tras el castigo de Licurgo (Radt, 1985, pp. 259-60). Uno de los escasos fragmentos conservados puede referirse a Licurgo (fr. 146b R.) (Sommerstein, 2008, p. 155), pero no sabemos en qué contexto. El coro, como indica el título, estaba conformado por muchachos jóvenes, quizá efebos conversos al servicio de Dioniso (Jouan, 1992, p. 75) o de Apolo, que podrían ser el instrumento para restablecer el equilibrio entre Apolo y Dioniso, cimentando el culto de ambos en Tracia (West, 1990, p. 47).

\subsection{Danaides. Esta tetralogía estaba formada por Egipcios, Suplicantes, Danaidesy el drama satírico Amímona. ${ }^{4}$}

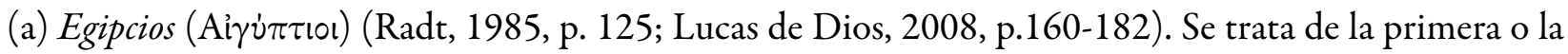
segunda tragedia de la tetralogía esquilea sobre las Danaides. Pese a que sólo ha sobrevivido una palabra de 
esta tragedia, el título en plural apunta a que el coro probablemente estaría formado por varones naturales de Egipto, bien los hijos de Egipto (Lloyd-Jones, 1957, p. 572), bien notables egipcios (Sommerstein, $2010^{2}$, p.

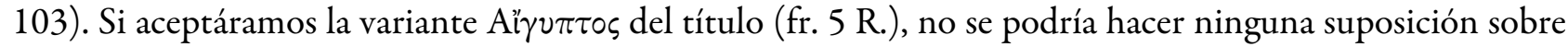
la identidad del coro (Taplin, 1977, p. 197 n.1).

(b) Danaides ( $\Delta \alpha \nu \alpha i ̈ \delta \varepsilon \varsigma)$ (Radt, 1985, pp. 157-161; Lucas de Dios, 2008, pp. 252-273). Se trata del tercer drama de la teatralogía sobre las Danaides. El coro estaba compuesto por las Danaides, al igual que en Suplicantes, por lo que también en esta obra actuaría como uno de los personajes principales del drama. Es muy probable que, antes de la párodo del coro propiamente, interviniera un coro suplementario mixto ${ }^{5}$ que cantara una albada ( $\delta \varepsilon \gamma \varepsilon p \tau \iota \kappa o ́ v)$ junto a las puertas de la cámara nupcial para despertar a los novios, según podemos deducir del fr. $43 \mathrm{R}$., en el que alguien (¿un sirviente? ¿Dánao?) invita a cantar a mozos y mozas (Garvie, 2006, pp. 228-229). La ironía trágica presente en la situación que supone celebrar con una canción

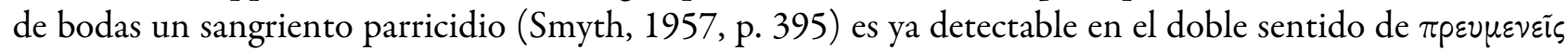

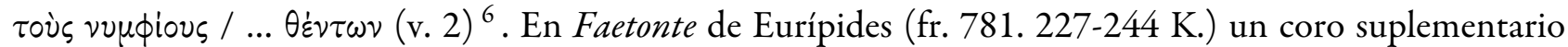
formado por doncellas, guiado y animado por Mérope (fr. 781.217-218 K.), canta un epitalamio para celebrar las bodas de Faetonte, precisamente cuando Faetonte ya está muerto. En cuanto al carácter mixto del posible coro secundario de Danaides, existe el paralelo de Eurípides, Hipólito 1104-1150, en el que el coro principal de la obra, compuesto por doncellas, parece cantar en antífona con un coro masculino. A ello habría que sumar el coro de niños varones, hijos de los Siete, que en Eurípides, Suplicantes 1123-1164 se alterna en el canto con el coro de ancianas madres (Swift, 2010, pp. 262-265). Es digno de atención que, como ocurre con Danaides, en ambos casos el contexto es luctuoso o preludia un desastre.

2.3. Prometeo. Esta polémica trilogía de Esquilo, que tantos ríos de tinta continúa provocando, pudo estar compuesta por Prometeo portador del fuego, Prometeo encadenado, Prometeo liberado y un drama satírico desconocido. $^{7}$

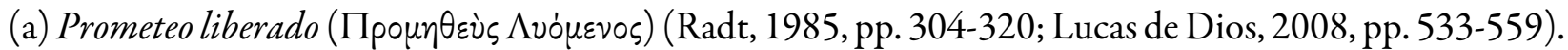
Esta tragedia continuaba la historia de Prometeo justo después de los sucesos de Prometeo encadenado (escolio a Esquilo, Prometeo encadenado 511). El coro estaba formado por los propios Titanes, hermanos de Prometeo (fr. 193.1-2 R.), a los que Zeus ha liberado de su encierro en las profundidades de la tierra (Sommerstein, 2008, p. 197) y que vienen a visitar a su hermano martirizado tras cruzar enormes distancias geográficas desde los confines orientales del globo (frs. 190, 191 R.). La tragedia comenzaba directamente con la párodo del coro (Arriano, Periplo 19.2). Que una tragedia empezara directamente con la párodo del coro o con el prólogo de un actor no tenía, en tiempos de Esquilo, ninguna vinculación con el mayor o menor arcaísmo de la técnica dramática, ya que ambas posibilidades estaban ya bien desarrolladas dramáticamente (Taplin, 1977, pp. 61-63).

\subsection{Aquiles ("Illíada dramática"). Esta tetralogía estaba formada por Mirmidones, Nereidas, Frigios y un drama satírico que pudo haber sido Los constructores de tálamos. ${ }^{8}$}

(a) Mirmidones (Mvpuióves) (Radt, 1985, pp. 239-257; Lucas de Dios, 2008, pp. 425-447). Esta tragedia dramatizaba los cantos IX-XVIII de la Ilíada. El coro estaba formado por Mirmidones, tropas procedentes de Ftía leales a Aquiles. El drama, al parecer, comenzaba con la párodo del coro de soldados (escolio a Aristófanes, Ranas 992), que rogaba a Aquiles con insistencia que rompiera su pétreo silencio y salvara a los aqueos (frs. 131, 132 R.). Sobre el llamado "silencio esquileo" véase infra apartado 3.8 (Niobe). 


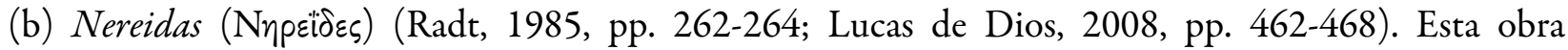
dramatizaba los cantos XIX-XXIII de la Iliada. El coro estaba formado por un grupo de Nereidas, que entraban en escena acompañando a Tetis con la nueva armadura para Aquiles (fr. 150 R.). Compárese con la párodo de Coéforos, en la que el coro escolta la entrada de Electra, que trae lo necesario para hacer libaciones (vv. 16-18, 22, 84-86) (Taplin, 1977, pp. 336-337). Una serie de pinturas vasculares (LIMC s.v. Achilles nos. 510-525) apunta a que las Nereidas pudieron entrar en escena subidas a delfines, como las Oceánides en carros alados en Esquilo, Prometeo encadenado 129-130, 279-281, aunque no cabe descartar que las pinturas vasculares simplemente plasmaran pictóricamente la imaginería presente en el texto (fr. 150 R.) (Sommerstein, 2008, p. 157 n. 1). El coro también pudo describir o imaginar el combate de Aquiles contra Héctor (fr. 152 R.): compárese con la descripción de la batalla que hace el coro de doncellas en Esquilo, Siete contra Tebas 151-165.

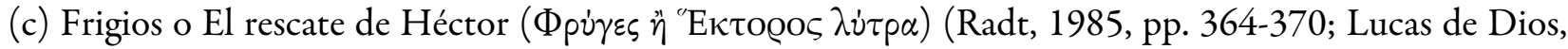
2008, pp. 652-663). Esta tragedia se corresponde con bastante exactitud con el argumento del canto XXIV de la Ilíada. El coro estaba formado por ciudadanos troyanos, tal y como apunta el título, que acompañaban

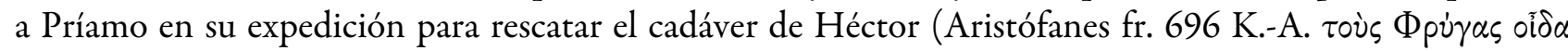

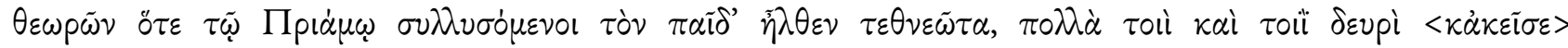
$\sigma \chi \eta \mu \alpha \tau i \sigma \alpha \nu \tau \varepsilon \varsigma)$. La coreografía creada por Esquilo para el coro de troyanos debió de ser espectacular, ya que Aristófanes la recordaba mucho tiempo después del estreno. Es de suponer que el coro reforzaría con su canto y su danza la súplica y los lamentos de Príamo ante Aquiles.

\subsection{Odiseo. Esta tetralogía estaba compuesta por Psicagogos, Penélope, Ostólogos y el drama satírico Circe. ${ }^{9}$}

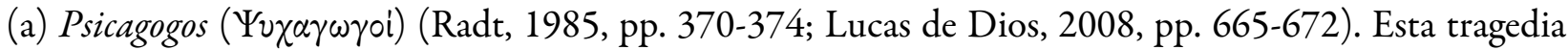
dramatizaba la llamada vékvı del canto 11 de la Odisea (fr. 275 R.). La escena del drama era un lago junto a la entrada al Inframundo (frs. 273, 273a R.) (Radt, 1985, p. 371). El coro estaba conformado por devotos

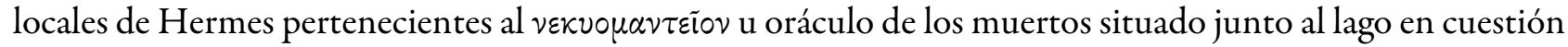
(fr. 273 R.). Verosímilmente la tragedia empezaba con la párodo del coro (Sommerstein, 2008, p. 271). Entre las funciones del coro en este drama estaba la muy importante de instruir a Odiseo en los ritos necrománticos con los que debe invocar a Tiresias (fr. 273a R.). Compárese con la invocación formal del fantasma de Darío que lleva a cabo el coro de persas en Esquilo, Persas 623-680.

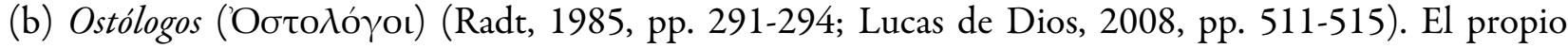
título de la obra ("recogedores de huesos") desvela que el argumento del drama era la recuperación de los cadáveres de los pretendientes de Penélope, muertos por Odiseo (Odisea XIV.413-17) (Radt, 1985, p. 291). Este drama era una tragedia, no un drama satírico (Sommerstein, 2008, pp. 179, 181). El coro estaría formado, verosímilmente, por los familiares de los pretendientes, que acudieron a pedir cuentas a Odiseo y a recoger los huesos de sus parientes tras su cremación. Posiblemente habría urnas funerarias visibles en

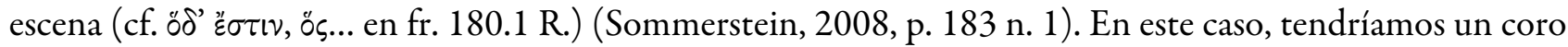
hostil y antagonista del personaje principal, Odiseo, tal y como ocurre con el coro de Erinis con respecto a Orestes en Euménides.

\section{6. Áyax. Esta trilogía estaba compuesta por El juicio de las armas, Tracias y Mujeres de Salamina. Desconocemos qué obra ocupaba el puesto de drama satírico. ${ }^{10}$}

(a) Juicio de las armas ("O $\pi \lambda \omega \nu$ kpiбis) (Radt, 1985, pp. 288-291; Lucas de Dios, 2008, pp. 506-510). El asunto de esta tragedia era, como su nombre indica, la competición por las armas de Aquiles entre Áyax y Odiseo (Radt, 1985, p. 288). Se podría postular que el coro estaba integrado por Nereidas: el escolio 


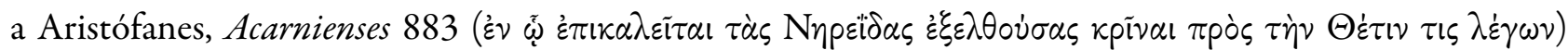
testimonia que el personaje que pronuncia el fr. $174 \mathrm{R}$. (¿Áyax?) invita a Tetis y las Nereidas a asistir y juzgar la competición. De hecho, Tetis tenía un papel destacado en la obra al traer la armadura de Aquiles (fr. 174 R.). De ser así, el coro de Nereidas desempeñaría el papel de uno de los personajes principales del drama, en este caso el de jurado. Compárese con el coro secundario de escoltas de Euménides 1032-1047, que antes había ejercido de jurado en el juicio de Orestes (vv. 482-484, 57) (Taplin, 1977, 411).

(b) Tracias $(\Theta p \tilde{\eta} \iota \sigma \alpha \iota)$ Radt, 1985, pp. 205-208; Lucas de Dios, 2008, pp. 359-365). Esta obra, que seguía a El juicio de las armas, dramatizaba el suicidio de Áyax. El coro estaba formado por mujeres tracias cautivas de guerra, mientras que el de Ayax de Sófocles presentaba a soldados de Salamina, compatriotas de Áyax, en ese papel (escolio a Sófocles, Ayax 134). En opinión del escoliasta, el coro de cautivas de Tracias era

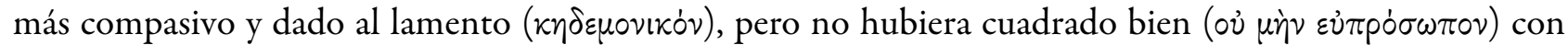
la libertad de palabra y el vigor en el enfrentamiento que el drama de Sófocles requería del coro. Por tanto, cabría deducir que el coro de cautivas en Tracias se comportaría de un modo semejante a las esclavas de Aquiles lamentando la muerte de Patroclo con trenos (Ilíada XIX.301), que el propio origen asiático de las mujeres haría más espectaculares y sentidos (cf. Swift 2010, pp. 328-329). Un eco de la posible inspiración iliádica en la conformación del coro de Tracias sería el fr. $84 \mathrm{a}$ R., en el que el coro de cautivas tracias elogia con sentimiento la amabilidad y bonhomía del muerto: compárese con el elogio de la gentileza del fallecido Patroclo que hace otra cautiva frigia, Briseida (Iliada XIX.287-300).

(c) Mujeres de Salamina ( $\sum \alpha \lambda \alpha \mu i v i \alpha$ ) (Radt, 1985, pp. 333-335; Lucas de Dios, 2008, pp. 592-594). El argumento del drama era el regreso de Teucro, hermanastro de Áyax, a su hogar en Egina (fr. 215a R.), del que su padre Telamón lo expulsa por no haber impedido la muerte de Áyax (Radt, 1985, p. 333). El coro estaba formado por mujeres naturales de Salamina. Este hecho, junto con el fr. 216 R., en el que alguien indica

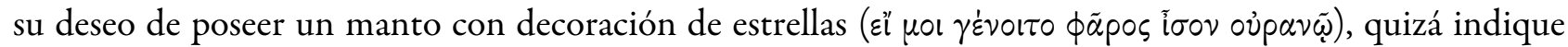
que un personaje femenino desempeñaba algún papel en la obra. Hesíone, madre de Teucro y concubina de Telamón, sería una posible candidata. Dado que la descripción de ropajes lujosos suele figurar en los cantos de vírgenes ( $\pi \alpha \rho \theta \dot{\varepsilon} v \varepsilon ı \alpha)$ como signo distintivo del atractivo matrimonial de una joven (Swift, 2010, p. 190), quizá el manto estrellado podría recordar a Hesíone, concubina y no esposa, la ceremonia de bodas que nunca tuvo. ${ }^{11}$ Compárese con la atención que, en Electra de Eurípides, la protagonista, casada en falso y avejentada, presta a sus tristes harapos (vv. 184-185) y a su falta de ropajes y joyas suntuosas, que le impiden participar en las danzas del resto de novias argivas (vv. 175-180).

El catálogo mediceo ha transmitido el título una vez más en masculino $\left(\sum \alpha \lambda \alpha \mu i v i o l\right)$, pero todos los autores griegos que citan fragmentos de esta obra mencionan un título en femenino, por lo que cabe deducir que el copista cometió un error (Sommerstein, 2008, p. 222).

\subsection{Memnón ("Etiópida trágica"). Podrían formar parte de una trilogía sobre los acontecimientos posteriores a la muerte de Héctor las tragedias Carios, Memnón y Psicostasia. ${ }^{12}$}

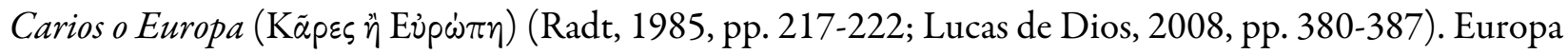
espera con ansiedad noticias sobre su hijo Sarpedón, que ha partido a la guerra de Troya (fr. 99 R.), de forma similar a como ocurre con la reina Atosa en Persas. El coro, como demuestra el título, estaba formado por varones de Caria, conciudadanos de Sarpedón, que, de modo similar al coro de dignatarios persas en Persas, presta oído a las quejas y muestras de ansiedad de la madre (fr. 99 R.), trataría de consolar su aflicción (cf. fr. 100 R.) (Radt, 1985, p. 222) y probablemente sería el protagonista del lamento fúnebre final por el cadáver

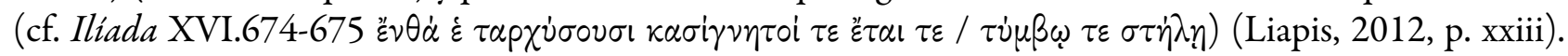
Es cierto que el cuerpo de Sarpedón fue transportado a Licia (Ilíada XVI.683), no a Caria, pero Estrabón 14.3.3 comenta que, por error o por deseo, Esquilo y otros tragediógrafos confundían carios con licios. Una 
razón para tal confusión es que los lamentos fúnebres carios eran realmente espectaculares, y verosímilmente Esquilo se beneficiaría de ello para añadir espectáculo y emoción al final de su tragedia (Smyth, 1957, p. 414).

\subsection{Epígonos. Esta trilogía estaría formada por Argivas, Eleusinios y Epígonos. Desconocemos qué drama satírico podría acompañarlas (quizá Nemea). ${ }^{13}$}

(a) Argivas (Ạץeĩal) (Radt, 1985, pp. 133-134; Lucas de Dios, 2008, pp. 211-215). Esta tragedia trataba sobre el resultado desastroso de la expedición de los Siete contra Tebas desde la perspectiva de los argivos derrotados. Pertenecía a la misma trilogía que Eleusinios, pero no está claro qué posición ocupaba. El fr. 17 R., que contiene un lamento lírico sobre los restos del cadáver de Capaneo, indica que el treno por los héroes caídos ante Tebas formaría parte del argumento y representaría el regreso de Adrasto a Argos con los cadáveres o cenizas de los Siete (cf. Eurípides, Suplicantes 1185-1188) (Sommerstein, 2008, p. 10). El coro estaría formado por ciudadanas de Argos, tal vez las madres de los Siete (en tal caso, el coro de Suplicantes de Eurípides sería un eco de esta tragedia) o las esposas de los Siete (lo que explicaría la sorprendente aparición de Evadne en Eurípides, Suplicantes 990-1071) (Aélion, 1983, p. 233). La función del coro como portavoz del lamento comunitario por un cadáver, propio de la tragedia más temprana, aparece no sólo en Argivas, sino también en Heliades y Tracias (Taplin, 1977, p. 179 n.).

En el catálogo mediceo y en algunos testimonios el título se transmite como Ạүeĩo (véase Radt, 1985, p. 133 sobre el fr. 17 R.). De ser esta la lectura correcta, el coro estaría formado por varones (¿quizá ancianos?) de Argos, que, de acuerdo con la estructura de un drama de regreso (nostos play) ${ }^{14}$, estarían a la espera de recibir noticias sobre la expedición; dichas noticias acabarían confirmando la derrota y la muerte. Compárese con el coro de ancianos persas en Persas, que se reúne a aguardar nuevas y reflexionar sobre la suerte del ejército de Jerjes (vv. 14-15, 140-149).

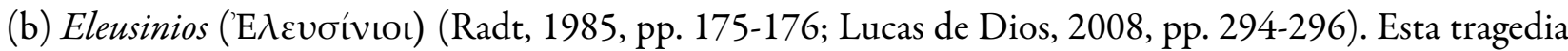
dramatizaba sustancialmente la misma área mítica que Suplicantes de Eurípides, esto es, la recuperación de los cadáveres de los Siete con ayuda de Teseo y los atenienses ante la resistencia tebana (fr. 53a R.), con interesantes diferencias de enfoque. El título de la tragedia aclara que el coro estaría formado, a diferencia del grupo de las madres de los Siete en Suplicantes de Eurípides, por varones naturales del demo de Eleusis, patria de Esquilo (compárese con el coro de varones nativos de Maratón de Heraclidas de Eurípides, otra obra de súplica y protección de los desvalidos a mayor gloria de Atenas). Posiblemente la naturaleza masculina del coro apunta a que la negociación, la persuasión o la amenaza de una guerra tendrían más peso entre los temas del drama que el lamento o la compasión (elementos estos que quizá formarían parte integral de Argivas, perteneciente a la misma trilogía).

(c) Epígonos (Exirovol) (Radt, 1985, p. 177; Lucas de Dios, 2008, pp. 296-298). Esta tragedia dramatizaría la toma de Tebas por parte de los Epígonos, hijos de los Siete contra Tebas, en venganza por la muerte de sus padres y para corregir la derrota de la expedición inicial (cf. Eurípides, Suplicantes 1213-1226). Desconocemos el argumento exacto de la tragedia. No hay pruebas ciertas de la composición del coro, pero dado el título en masculino plural, podríamos concluir que lo formaban los Epígonos, quizá a excepción de Alcmeón, por lo que de nuevo estaríamos ante el caso de un coro que desempeña uno de los papeles principales.

2.9. “Tetralogía tebana” (Dodds, $1960^{2}$, p. xxix). No está claro si las tragedias Bacantes, Cardadoras, Penteo, Sémele y Arqueras forman parte de una o varias trilogías o tetralogías sobre Dioniso, a lo que habría que sumar además el drama satírico Nodrizas. Hay distintas teorías (Radt, 1985, pp. 116-117; Jouan, 1992, pp. 76-79). 


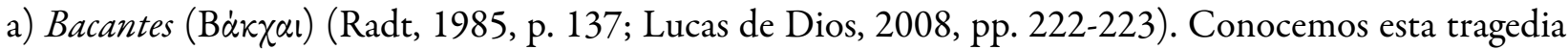
únicamente por el catálogo mediceo y por una sola cita (fr. 22 R.) que no desvela su argumento. Evidentemente, el coro estaría formado por bacantes, devotas de Dioniso, como en la tragedia homónima de Eurípides. No se puede descartar que sea un título alternativo de otras tragedias esquileas de tema dionisíaco como Basárides, Cardadoras o Penteo, o incluso el propio nombre de la tetralogía sobre Dioniso (Radt, 1985, p. 137).

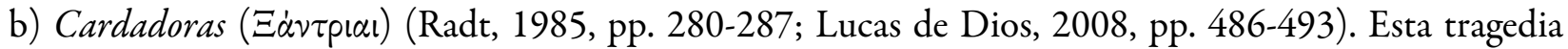
trataba sobre la muerte de un oponente de Dioniso, posiblemente Penteo (fr. 172b R.) a manos de las bacantes. El título ("cardadoras") hace referencia al coro de mujeres tebanas, que han abandonado su hogar y sus ocupaciones domésticas y típicamente femeninas, como la rueca y el telar, para correr al monte en la celebración de los ritos de Dioniso (cf. Eurípides, Bacantes 118-119). ${ }^{15}$ De cumplirse la tendencia observada por Dodds $\left(1960^{2}\right.$, p. xxx n.1), en el sentido de que los títulos trágicos descriptivos se refieren a la situación al principio de la tragedia (e.g. Coéforos, Rastreadores, Hipólito portador de la corona, Lavanderas, etc.), “cardadoras" aludiría a cómo se presentaba o describía inicialmente el coro.

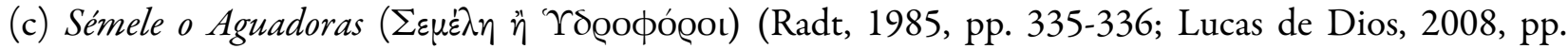
595-600). Esta tragedia versaba sobre el nacimiento de Dioniso (escolio aApolonio de Rodas 1.636) y la muerte de su madre Sémele (fr. 220a 16-30 R.). El coro estaba formado por mujeres, seguramente sirvientas, que habían venido a ayudar a Sémele durante el parto. Según testimoniael escolio a Apolonio de Rodas

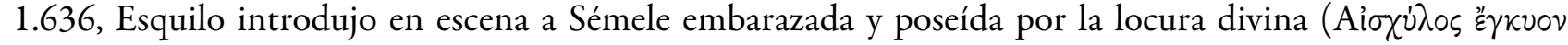

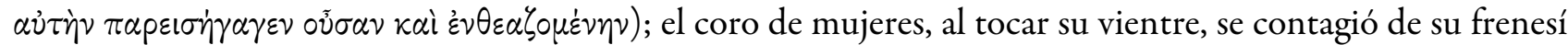

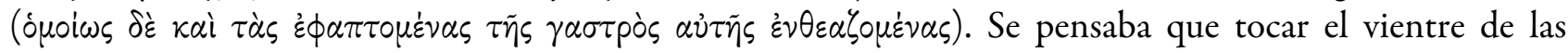
parturientas aliviaba los dolores del parto gracias al calor de las manos (Sorano, Ginecología 2.4.1). El coro, además, trae agua con la que lavar al recién nacido (cf. Plauto, Anfitrión 1102-1103). Cabe deducir que el coro ejecutaría una coreografía muy espectacular (cosa por la que era famoso Esquilo), quizá aprovechando los jarros de agua como el coro de sirvientas en Esquilo, Coéforos 22-31 y Electra en Eurípides, Electra 107-109 (Taplin, 1997, p. 337 n. 1).

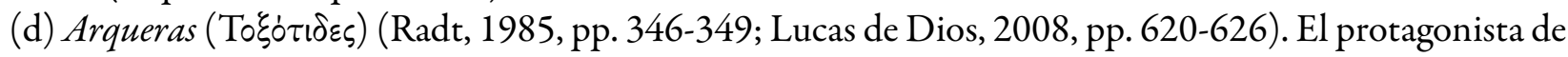
este drama era Acteón (frs. 241 R.), sobrino de Sémele. La tragedia trataba su transformación en ciervo por obra de Ártemis y su muerte, devorado por sus propios perros de caza (fr. 244 R.). Según el título, el coro

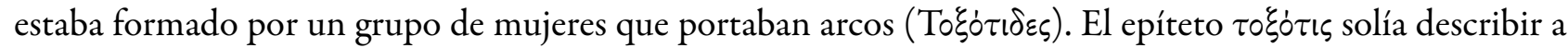
Ártemis (escolio a Eurípides, Fenicias 109) o a Atalanta (Calímaco, Himno a Ártemis 223), ambas cazadoras. Por tanto, los miembros del coro representarían a jóvenes ninfas, compañeras de Ártemis, que seguían a la diosa en sus cacerías (Radt, 1985, p. 346). Coros de ninfas (de distintos tipos) aparecen también en Prometeo Encadenado, Nereidas, Etneas y Heliades (Poli-Palladini, 2001, p. 313). El coro sería, evidentemente, poco amistoso con Acteón. Otro coro poco simpatético con el protagonista principal es, por ejemplo, el coro de Bacantes de Eurípides, formado por bacantes, servidoras de Dioniso, que se enfrentan a Penteo.

\subsection{Argonautas. Esta tetralogía estaba formada por Lemnias, Hipsípila, Cabiros y el drama satírico Argo o los remeros. ${ }^{16}$}

(a) Lemnias $(\Lambda \dot{\eta} \mu \nu$ เ $)$ (Radt, 1985, pp. 233-234; Lucas de Dios, 2008, pp. 414-416). Esta tragedia trataría sobre el llamado "crimen lemnio", a saber, el asesinato de todos los varones de Lemnos a manos de las mujeres de la isla (Esquilo, Coéforos 631-637) (Radt, 1985, p. 233). El coro estaría formado por un grupo de mujeres lemnias (compárese, por ejemplo, con el coro de Danaides en Danaides, formado por las asesinas de sus maridos).

El catálogo mediceo denomina a la tragedia en masculino, $\Lambda \dot{\eta} \mu \nu \iota \iota$, verosímilmente por error, como ocurre con otros títulos como Argivas y Mujeres de Salamina (Sommerstein, 2008, pp. 126-127). Algunos estudiosos 
han tomado como lectura correcta el título masculino y han preferido asociar esta tragedia no con el ciclo de los Argonautas, sino con Filoctetes. ${ }^{17}$

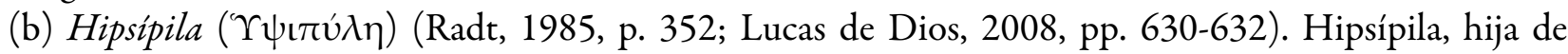
Toante, rey de Lemnos, acaudilló la rebelión de las mujeres de Lemnos contra los varones de la isla, a los que acabaron exterminando. La tragedia, según el escolio a Apolonio de Rodas 1.769-773, dramatizaba la visita de los Argonautas a Lemnos durante la expedición en busca del vellocino de oro. Apenas han quedado fragmentos significativos, pero el escolio mencionado aporta información interesante. Las mujeres de Lemnos, fuertemente armadas, impidieron el desembarco de los Argonautas, que estaban siendo azotados por una tormenta, hasta que estos se comprometieran a tener relaciones sexuales con ellas. A diferencia de lo que ocurre en Lemnias de Sófocles, donde las mujeres de Lemnos y los Argonautas llegaron a trabar combate, en el drama de Esquilo el conflicto entre hombres y mujeres parece haberse resuelto mediante un acuerdo negociado. En este sentido, el acuerdo, la persuasión y la negociación como solución a la guerra entre los sexos, tema de fondo de Lemnias e Hipsípila, recuerdan a la temática de la tetralogía de las Danaides (Sommerstein, 2010², pp. 106-107).

Aunque no hay seguridad completa por la falta de testimonios precisos, cabría postular, gracias al escolio, que el coro de la obra pudo haber estado formado o bien por los Argonautas o bien por las mujeres de Lemnos, armadas y listas para actuar (compárese con el doble sentido de las palabras del coro de Danaides en Suplicantes 21). Me inclino, aunque sin mucha confianza, por la segunda posibilidad, debido a que la protagonista de la tragedia, al menos según demuestra el título, es Hipsípila, no Jasón.

c) Cabiros (Kর́ß̊ııрo) (Radt, 1985, pp. 214-216; Lucas de Dios, 2008, pp. 376-379). Esta tragedia (no drama satírico ${ }^{18}$ ) tenía como argumento algún episodio de la expedición de los Argonautas en busca del vellocino de oro, ya que incluía un catálogo con el nombre de todos los Argonautas (escolio a Píndaro, Píticas 4.303). Si el drama trataba sobre la visita de los Argonautas a Lemnos y la celebración de las bodas entre Hipsípila y Jasón, narraría los acontecimientos posteriores a Hipsipila. ${ }^{19}$

Según la noticia de Ateneo 10.428F, Jasón y sus compañeros aparecían borrachos en escena, una innovación de Esquilo que causó, al parecer, bastante polémica. Sin embargo, el coro no estaba formado por los Argonautas, sino por los propios Cabiros, ${ }^{20}$ quienes amenazaban jocosamente con causar una carestía de vinagre (fr. 97 R., probablemente recitado por el corifeo) y aseguraban que nunca faltaría el vino y el agua en la rica casa de alguno de los protagonistas del drama (fr. 96 R.). Una noticia intrigante de Focio, Léxico $\kappa 3$ nos informa de que los Cabiros se habían retirado de Lemnos, enojados por el crimen de las lemnias

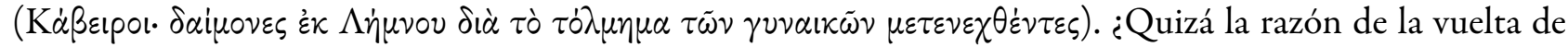
los dioses a Lemnos y su reconciliación con el culto de la isla se deba a la celebración de las bodas entre Hipsípila y Jasón, que borrarían la mancha del crimen lemnio anterior? En el contexto de tal regreso y de su participación en la celebración de las bodas entre Jasón e Hipsípila, el coro de Cabiros entonararía un canto de

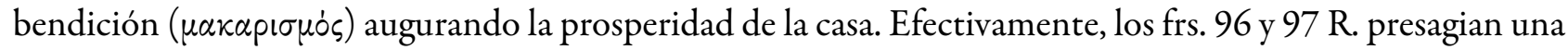
sobreabundancia en la cosecha de uva y en la producción de vino (Radt, 1985, p. 216; Smyth, 1957, p. 415). Un cierto paralelo de esta secuencia de ideas que postulo como argumento de Cabiros (cólera y retiro como situación inicial, persuasión y compensación como foco de atención dramática, reconciliación y celebración final) podría aportar la transformación del coro de Erinis en Euménides: las diosas, airadas ante lo que consideran un desafuero e injusticia que se les ha hecho, manifiestan su intención de causar el mayor mal que pueden a la tierra donde se ha cometido una flagrante violación de sus derechos (vv.778-792). Finalmente, deponen su cólera y deciden aceptar el culto que, en desagravio, les ha ofrecido Atena (vv.891-926). La reconciliación pacífica del conflicto entre los sexos y entre hombres y dioses se celebra con un himno final de alegría, bendición, prosperidad y fertilidad del mundo vegetal y animal (vv. 938-947, 956-967, 1033-1047) (Sommerstein, 2010², pp. 106-107, 134-135, 180). 
Si esta suposición fuera correcta, la actuación del coro de Cabiros cuadraría bien en una tragedia que tratara la resolución feliz del conflicto inicial entre las mujeres de Lemnos y los Argonautas, que se ventilaría en los dos dramas anteriores.

\section{Tragedias que Pertenecían a tetralogías y trilogías no CONECTADAS}

En este apartado dejaré constancia de aquellas tragedias que no parecen haber sido parte de una misma trilogía o tetralogía conectada por argumento, o sobre las que no hay pruebas suficientes para asignarlas con fiabilidad a una de ellas.

3.1. Etneas (Aĩvaĩal) (Radt, 1985, pp. 126-129; Lucas de Dios, 2008, pp. 182-190). Esta tragedia debió de ser una de las más curiosas y sorprendentes de Esquilo. Vida de Esquilo 9 nos informa de que se estrenó en Sicilia a instancias de Hierón, para celebrar y augurar bienes a la fundación de la ciudad de Etna. No se conoce el argumento completo de la obra, 21 aunque al menos una escena trataba sobre las relaciones de la ninfa siciliana Talía con Zeus, su embarazo y ocultación bajo la tierra y el regreso de sus hijos, los dioses Palicos a la luz del sol

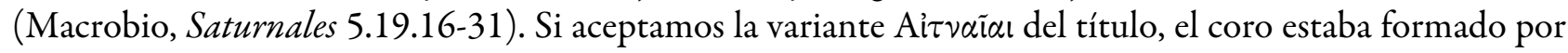
personajes femeninos, quizá ninfas del monte Etna, hermanas o compañeras de Talía, que podrían peregrinar en su busca (Poli-Palladini, 2001, p. 304). En caso de que la lectura correcta del título fuera Aḯvaı (véase frs. 7-8 R.), no habría forma de conocer la composición del coro, ya que el título aludiría simplemente a la localización del drama (quizá el volcán junto con la ciudad).

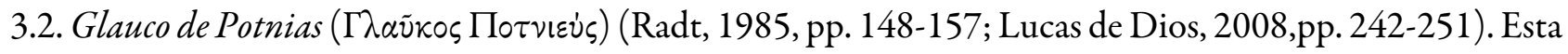
tragedia, perteneciente a la tetralogía formada además por Fineo, Persas y Prometeo encendedor del fuego, trata sobre Glauco de Potnias, que murió devorado por las yeguas que tiraban de su carro durante una carrera en los juegos fúnebres en honor de Pelias. Durante la obra, un personaje, quizá la mujer de Glauco o el propio coro, trataba de disuadir al protagonista de su afán por participar en los juegos fúnebres (cf. fr. 37 R.), como el coro con Eteocles en Siete contra Tebas 686-719 (Taplin, 1977, p. 162 n.2), posiblemente por culpa de algún sueño o aparición nocturna (cf. fr. 36b 2, I 10 R.). El coro, además, podría funcionar como intérprete del sueño, o aliviar el miedo de quien lo había tenido, de forma semejante al coro en Persas 159-225 (Garvie, 2009, p. xliv). Por lo demás, el coro estaba formado por ciudadanos de Potnias, quienes acompañaban con himnos y deseos de buen viaje la salida de Glauco hacia los juegos (fr. 36 R.), augurios estos que resultaron trágicamente fallidos: lo que parece anticiparse a la técnica sofoclea de situar un estásimo exultante de felicidad justo antes de desvelar una catástrofe (sobre la cual véase Garvie, 1998, p. 192). Posiblemente se trataba de un $\pi \rho o \pi \varepsilon \mu \pi \tau \iota k o ́ v$, un himno cantado para despedir y augurar bien durante un viaje, parodiado en el regreso de "Esquilo" a la luz en Aristófanes, Ranas 1528-1529 (Sommerstein, 2008, p. 34 n.1).

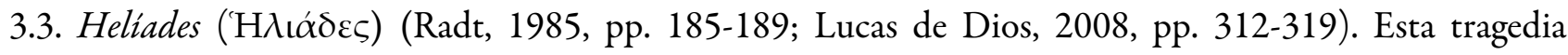
trataba el mismo mito que Faetonte de Eurípides, a saber, la muerte de Faetonte mientras conducía el carro de su padre el Sol. El coro estaba formado por las Helíades, las hermanas de Faetonte. La tragedia probablemente empezaba directamente con la entrada del coro, que recitaba unos anapestos de contenido geográfico (fr. 68 R.) (Sommerstein, 2008, p. 71). Uno de los estásimos del coro (fr. 69 R.) celebraba el conocido viaje nocturno del Sol en su copa de oro. Es posible que, en una de sus intervenciones líricas finales, el coro de Helíades 


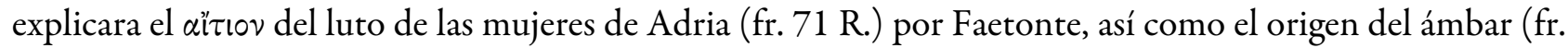
72 R.).

3.4. Heraclidas ('H@ $\alpha \kappa \lambda \varepsilon i ́ \delta \alpha \iota)$ (Radt, 1985, pp. 190-193; Lucas de Dios, 2008, pp.319-329). No está clara el área del mito de Heracles que trataba esta tragedia ni si pertenecía a una tetralogía conectada. Lo único que cabe afirmar con certeza es que aparecía Heracles, posiblemente ex machina y ya divinizado (frs. 73b, 75a R.), narrando su muerte en la pira (Hannemann, 1999, p. 72). El parlamento de Heracles en fr. 73b.4 R. se refiere a sus hijos con el deíctico oíde, lo que indica que están en escena, y aunque el título de Heraclidas parece apuntar a que el coro estaría formado por los propios hijos de Heracles, el paralelo con la homónima Heraclidas de Eurípides (tuviera el mismo argumento o no) aconseja en este caso extremar la cautela: en la tragedia euripidea el coro está formado por habitantes de Maratón y los Heraclidas, que dan nombre a la tragedia, son un grupo de extras mudos. Lo mismo podría ocurrir en la tragedia de Esquilo.

3.5. Sacerdotisas (Ić@eı $\alpha \iota)$ (Radt, 1985, pp. 208-210; Lucas de Dios, 2008, pp. 365-367). Desconocemos prácticamente todo sobre el argumento de esta tragedia (Radt, 1985, p. 209). Lo único que se sabe con

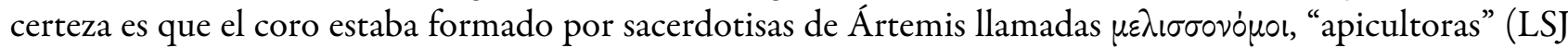
II.2 s.v. $\left.\mu \dot{\varepsilon} \lambda \_\sigma \sigma \alpha\right)$ (Sommerstein, 2008, pp. 102-103 n. 1) y que entra en escena con la intención de abrir el templo de esta diosa (fr. 87 R.). Este podría ser el propio comienzo del drama; de ser así, sería una de las párodos motivadas por el cumplimiento de un ritual o una actividad religiosa, como en Eurípides, Bacantes 69-72, Cretenses fr. 472 K. e Ifigenia entre los Tauros 126-142 (Taplin, 1977, p. 422).

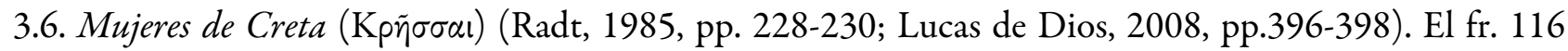
R. de esta tragedia demuestra que su argumento era el mismo que el de Adivinos de Sófocles y Poliído de Eurípides (Radt, 1985, p. 228). El coro estaba formado por mujeres cretenses. Sommerstein (2008, p. 337) considera que el fr. $451 \mathrm{~h} \mathrm{R}$., un lamento lírico de un coro femenino, podría proceder de esta obra. En tal caso, el coro femenino, de forma típica, se lamentaría y lloraría por el aciago destino del joven Glauco y por los sufrimientos de su padre, el hospitalario Minos.

3.7. Misios (Mvooi) (Radt, 1985, pp. 257-259; Lucas de Dios, 2008, pp. 447-453). Este drama podría haber formado parte de la misma trilogía que Télefo (Radt, 1985, p. 115), pero igualmente podrían haberse estrenado en años diferentes. La tragedia versaba sobre la llegada de Télefo a Misia (Aristóteles, Poética 1460a30-32). Sabemos por el testimonio de Aristóteles que Télefo guardó silencio durante el viaje, aunque no cabe descartar que el prólogo estuviera en boca de Télefo (fr. 143 R.), que lo recitaría en soledad, antes de que entrara el coro (Taplin, 1977, p. 424). Dicho coro, según el título de la obra, estaría formado por varones misios, quizá conectados con el sacerdote del río Caíco al que se dirige el fr. $144 \mathrm{R}$.

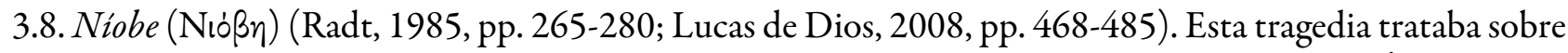
los sufrimientos de Níobe, hija de Tántalo, cuyos hijos habían sido asesinados por Apolo y Ártemis para castigar la jactancia de su madre. No está clara la identidad del coro. Estaba formado por mujeres residentes en Tebas, no conectadas por familia con Níobe pero con una disposición benévola hacia ella (fr. 154a 5, 14-15 
R.) (Sommerstein, 2008, p. 163), que prestan oído paciente a los lamentos de la madre o nodriza de Níobe

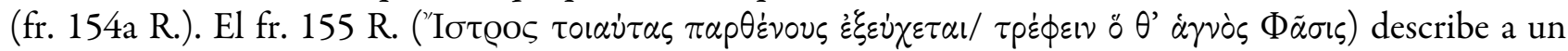
grupo de vírgenes parecidas a las naturales de los países regados por el río Istro o Fasis, es decir, amazonas (cf. Prometeo encadenado 415-416) (Sommerstein, 2008, p. 167). El verso podría entrañar una comparación con el aspecto del coro: recuérdese cómo Pelasgo asemeja la apariencia del coro de Danaides, que afirman ser argivas, con el físico de mujeres egipcias, chipriotas, indias o amazonas (Suplicantes 279-289), o cómo Polinices, notando el aspecto no griego del coro de mujeres, pregunta de dónde son (Eurípides, Fenicias 278-279).

Aristófanes (Ranas 911-926), burlándose de la técnica dramática de Esquilo, hacía que su Eurípides satirizara la tendencia esquilea de presentar personajes mudos e inmóviles en escena (vv. 911-913). El coro, decía, iba cantando largas tiradas corales y mientras tanto el drama iba transcurriendo (vv. 914-915), con el público atento y suspenso, esperando a que el personaje rompiera su silencio (vv. 919-920). Evidentemente, la caracterización que hace el Eurípides aristofaneo es poco caritativa y burlesca, pero tiene un grano de verdad: la interrelación entre el silencio del personaje (el llamado "silencio esquileo") y las intervenciones del coro tenía como propósito aumentar el suspense dramático y centrar el interés del espectador en la figura silenciosa en escena (Taplin, 1977, p. 112 n. 4). Son ejemplos de esta técnica, aparte de Niobe, Mirmidones, Frigios y Misios (Taplin, 1972, pp. 60-76).

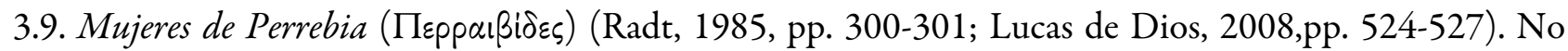
está claro si este drama era parte o no de la misma trilogía que Ixión. Esta tragedia dramatizaba la muerte traicionera de Eyoneo o Deyoneo, suegro de Ixión, a manos de su yerno (fr. 186 R.) cuando fue a reclamarle los costosos regalos que Ixión le había prometido por concederle la mano de su hija Día (frs. 184, 185 R.). Tras la muerte de su suegro, la locura rabiosa $(\lambda \dot{\nu} \sigma \sigma \alpha)$ se apoderó de Ixión; nadie, ni dios ni hombre, podía o quería purificarlo al ser el primer parricida de la historia (escolio a Apolonio de Rodas 3.62). El coro, según el título de la tragedia, estaba formado por mujeres oriundas de Perrebia, región tesalia donde estaba situada la ciudad de Girtón (Estrabón 9.5.19), sobre la que Ixión reinaba. Es aun así extraño encontrar un coro femenino en esta tragedia, dado que los protagonistas parecen ser dos varones, Ixión y Eyoneo. A este respecto, la composición del coro me induce a considerar que Día, la hija de Eyoneo y esposa de Ixión, podría desempeñar un papel importante en el drama. Cabría aducir el paralelo de Coéforos, protagonizado también por un parricida, Orestes, al que se compara explícitamente con Ixión (Euménides 441, 717-718): el coro de sirvientas tiene relación inicial con un personaje femenino, Electra, quien desaparece en mitad del drama y deja todo el protagonismo al personaje masculino, Orestes, y su parricidio. Al final de la tragedia, Orestes, como Ixión, sufre un ataque de locura. Por tanto, Día podría desempeñar una función dramática semejante a la de Electra en Coéforos (¿facilitar el engaño? ¿atraer a su padre a una trampa?).

3.10. Filoctetes ( tenía el mismo argumento que Filoctetes de Sófocles, que se ha conservado. Conocemos bastante bien la técnica dramática empleada por Esquilo gracias a la comparación que hizo Dión Crisóstomo 52 entre los tres Filoctetes de Esquilo, Eurípides y Sófocles. La obra empezaba con un prólogo pronunciado por Filoctetes (fr. 249 R.). El coro de la tragedia estaba formado, como en Filoctetes de Eurípides y a diferencia del de Sófocles, por varones oriundos de Lemnos (Dión Crisóstomo 52.7), isla en la que Filoctetes lleva nueve años abandonado. El coro de lemnios en Eurípides aparece en escena disculpándose por no haberse preocupado por la situación de Filoctetes durante tantos años (52.7), mientras que el coro de Esquilo simplemente entra

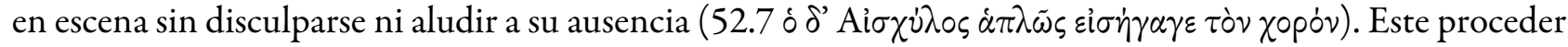

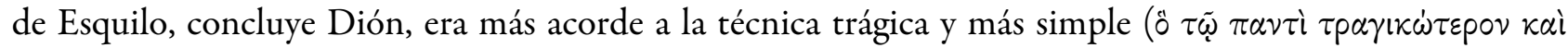




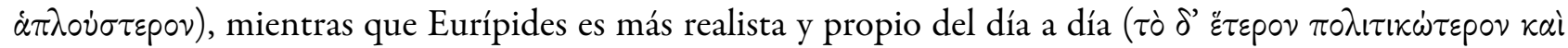
$\dot{\alpha} \kappa p(\beta \dot{\varepsilon} \sigma \tau \varepsilon \rho о \nu)$.

Las observaciones de Dión son preciosas para entender la técnica coral de Esquilo: no se pierde en detalles, que pueden ser necesarios en otros géneros pero no tanto en la tragedia, cumple las funciones dramáticas que le asigna la tragedia (en este caso, servir como receptor de información para que el personaje principal explique la situación trágica al público de forma orgánica, véase los frs. 250-252 R.), y no intenta reflejar un realismo a ultranza, que pueda resultar lesivo para el propósito dramático o desdibujar el centro de interés artístico de la tragedia (Taplin, 1977, pp. 68-70). En este sentido, el juicio crítico de Dión coincide bastante bien con el de Aristófanes en Ranas (cf. 959-961, 971-979) y con Vida de Esquilo 5-7.

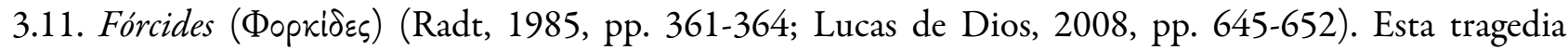
pertenecía al área mítica de Perseo, pero no está claro que formara parte de una tetralogía conectada junto con la tragedia Polidectes y el drama satírico Arrastradores de redes. Las Fórcides, las hijas de Forco, son las Greas, un grupo de tres deidades que compartían un ojo y un diente entre las tres y que servían de centinelas de sus hermanas las Gorgonas (Esquilo, Prometeo encadenado 793-800). En Fórcides, Perseo interceptó, cuando se lo estaban pasando entre ellas, el único ojo de las Greas y lo arrojó a la laguna Tritónide, en Libia, por lo que las diosas, cegadas, no pudieron avisar del peligro a las Gorgonas. Perseo las sorprendió dormidas dentro de su antro y decapitó a la inerte Medusa (Ps. Eratóstenes, Catasterismos 22). Por el título, cabría pensar que el coro estaba formado por las propias Greas. Los coros de Titanes en Prometeo liberado, de Nereidas en Nereidas y de Erinis en Euménides demuestran que sería posible formar un coro con divinidades menores. Pero no es posible imaginar cómo se desarrollaría el drama si el coro estuviera formado por las Greas: ¿̨cómo se escenificaría, por ejemplo, el robo del ojo? ¿Cómo actuaría un coro que hubiera quedado ciego a mitad del drama? Por este motivo, Sommerstein (2008, p. 261) sugería que el coro podría estar formado por ninfas del lago Tritónide, que aparecen en testimonios literarios (Ferécides fr. 11 Fowler) e iconográficos (LIMC s.v. Perseus no. 88). Otras tragedias con títulos en plural que no designan al coro, sino a un grupo de personajes importantes para la acción, son Siete contra Tebas de Esquilo, Heraclidas y quizá Pelíades de Eurípides.

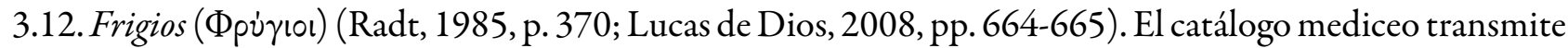

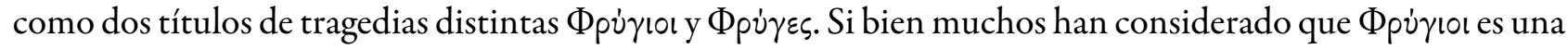
ditografía, es difícil imaginar que el copista cometiera un error tan grave estando los títulos tan próximos uno a otro, por lo que habría que aceptar la idea de que el catálogo transmite el título de una tragedia existente de la que no han quedado fragmentos (Wilamowitz, 1914, p. 8). De ser así, necesariamente debería pertenecer al ciclo troyano. Podría haber formado parte de la trilogía sobre Memnón con Carios y Memnón (véase supra apartado 2.7) y dramatizaría la muerte de Aquiles; en esta tragedia se incluiría el famoso lamento de Tetis sobre la falsedad de Apolo (fr. 350 R.) (Ganz 1980, pp. 220-222).

Hay, sin embargo, otras posibilidades. Habida cuenta de la práctica del copista, ya vista en Argivas, Lemnias y Salaminas, de poner en masculino títulos que el resto de testimonios citan en femenino, y teniendo en

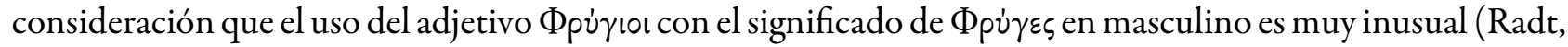

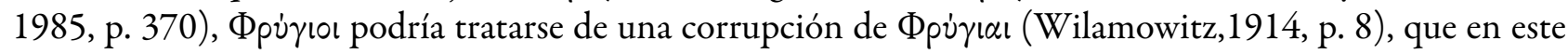
caso sería una tragedia distinta, cuyo coro estaría formado por cautivas troyanas (Sommerstein, 2008, pp. 264-265). 


\section{Conclusiones}

Recordemos que, de las siete tragedias transmitidas de Esquilo, el título de cuatro (57\%) hace referencia a la naturaleza, función e identidad del coro (Persas, Suplicantes, Coéforos, Euménides). Estas cifras están en línea con los resultados arrojados por la consulta de los fragmentos: de los 55 títulos de tragedias perdidas registrados, más de la mitad (29; 52\%) están en plural, por tanto referidos al coro. La mayoría de los títulos en plural aluden a la identidad o a la pertenencia geográfica del coro, aunque algunos de ellos desvelan también su ocupación (Básaras, Bacantes, Psicagogos, Ostólogos, Cardadoras, Sémele o Aguadoras, Arqueras, Sacerdotisas). La mayor proporción de títulos en plural, esto es, que denominen e identifiquen al coro, implicaría por lógica una mayor importancia de este en la acción dramática, sobre todo en comparación con la tragedia posterior.

De las siete tragedias conservadas, el coro de Esquilo desempeñaba un papel dramático coherente e importante en todas las obras menos en Prometeo encadenado. De hecho, en dos de ellas, Suplicantes y Euménides, el coro funciona a todos los efectos como un actor más, como prescribía Aristóteles. Esta impresión se ve confirmada por el testimonio de los fragmentos trágicos: así ocurre también en Danaides, Epígonos, Hipsípila, Cabiros, Ostólogos y quizá Heraclidas. En cuanto a la función dramática del coro, se repiten las que se observan en las tragedias conservadas: consuelo (Prometeo liberado, Niobe), lamento (Nereidas, Frigios, Argivas, Helíades, Tracias, Mujeres de Salamina, Carios), auxilio (Sémele, Filoctetes), oposición u hostilidad (Basárides, Ostólogos, Arqueras, Lemnias, Cabiros), persuasión (Mirmidones, Frigios, Glauco de Potnias, Niobe), súplica (Mirmidones, Frigios, Niobe), celebración de ritos (Psicagogos, Sacerdotisas), participación en un jurado (Juicio de las armas), búsqueda (Etneas).

Por otra parte, otra de las características por las que destaca el coro esquileo es por su variedad. En los siete dramas conservados de Esquilo encontramos coros masculinos (Persas, Agamenón) y femeninos (Siete contra Tebas, Suplicantes, Coéforos, Euménides, Prometeo encadenado), formados por mortales y por deidades (Euménides, Prometeo encadenado), por jóvenes vírgenes (Suplicantes, Siete contra Tebas, Prometeo encadenado) y por ancianos dignatarios (Persas, Agamenón), por sirvientas (Coéforos) y por consejeros (Persas), por griegos (Siete contra Tebas, Agamenón) y por bárbaros (Persas, Suplicantes, quizá Coéforos). Esto se ve confirmado por el testimonio de los fragmentos trágicos: hay coros masculinos (Egipcios, Glauco de Potnias, Eleusinios, Edonos, Heraclidas, Cabiros, Carios, Mirmidones, Misios, Jóvenes, Ostólogos, Prometeo liberado, Filoctetes, Frigios) y femeninos (Etneas, Argivas, Bacantes, Basárides, Danaides, Heliades, Tracias, Sacerdotisas, Mujeres de Creta, Lemnias, Nereidas, Niobe, Cardadoras, Juicio de las armas, Mujeres de Perrebia, Sémele, Arqueras), formados por divinidades (Etneas, Helíades, Cabiros, Nereidas, Juicio por las armas, Prometeo liberado, Arqueras) y por humanos, por jóvenes vírgenes (Heliades, Arqueras), mujeres casadas o madres (Argivas, Mujeres de Creta, Lemnias, Cardadoras, Mujeres de Perrebia), efebos (Jóvenes) y ancianos (Frigios), por cautivas (Tracias) y por soldados (Mirmidones), por bárbaros (Egipcios, Danaides, Edonos, Tracias, Carios, Misios) y por griegos, así como por sacerdotisas y miembros de un culto (Sacerdotisas, Bacantes, Basárides, Cardadoras, Psicagogos). Hay que destacar el interés que demuestra Esquilo por los rituales trenéticos de los pueblos no griegos (ya demostrado en Persas), verosímilmente escenificados en Carios, Tracias y Heliades, así como el empleo de espectaculares coreografías corales (El rescate de Héctor, Sémele). Como se puede ver, la diversidad de identidades y funciones en los coros de Esquilo es notable.

En conclusión, los fragmentos trágicos confirman la técnica de manejo del coro que ya conocemos por las tragedias conservadas de Esquilo: un coro imbricado directamente en la acción, diverso y multifuncional, que forma parte inextricable del todo que implica el drama.

\section{ReFERENCIAS}

Aélion, R. (1983). Euripide héritier d'Eschyle, tome 1. Paris: Les Belles Lettres. 
Cipolla, P. (2010). 'Frammento di Dike' (Aesch. F 281a R.): uno status quaestionis sui problemi testuali ed esegetici. Lexis 28, 133-154.

Deforge, B. (1987). Eschyle et la légende des Argonautes. REG 100, 33-44.

Dodds, E. R. $\left(1960^{2}\right)$. Euripides. Bacchae, Oxford: Oxford Univ. Press.

Gantz, T. (1980). Aischylos' Lost Plays: The Fifth Column. RhM 123, 210-222.

Garvie, A. F. (1998). Sophocles. Ajax. Warminster: Aris \& Phillips.

Garvie, A. F. (2006). Aeschylus' Supplices. Play and Trilogy. Exeter: Bristol Phoenix Press.

Garvie, A. F. (2009). Aeschylus. Persae, Oxford: Oxford University Press.

Hahnemann, C. (1999). Mount Oita revisited: Sophocles' Trachiniai in light of the evidence of Aischylos' Herakleidai. ZPE 126, 67-73.

Jouan, F. (1992). Dionysos chez Eschyle. Kernos 5, 71-86.

Liapis, V. (2012). A Commentary on the Rhesus Attributed to Euripides. Oxford - New York: Oxford University Press. Lloyd-Jones, H. (1957). Appendix. En H. W. Smyth. Aeschylus vol. 2. Cambridge (Mass.): Harvard Univ. Press.

Lucas de Dios, J. M. (1983). Sófocles. Fragmentos, Madrid: Gredos.

Lucas de Dios. J. M. (2008). Esquilo. Fragmentos y testimonios. Madrid: Gredos.

Mette, H. J. (1963). Der verlorene Aischylos. Berlin: Akademie Verlag.

Poli-Palladini, L. (2001). Some reflections on Aeschylus “Aetnae(ae)”. RhM 144, 287-325.

Radt, S. (1985). Tragicorum Graecorum Fragmenta vol. 3. Aeschylus. Göttinger: Vandenhoeck \& Ruprecht.

Smyth, H. W. (1957). Aeschylus vol. 2. Cambridge (Mass.): Harvard Univ. Press.

Sommerstein, A. H. (2008). Aeschylus. Fragments. Cambridge (Mass.) - London: Harvard Univ. Press.

Sommerstein, A.H. $\left(2010^{2}\right)$. Aeschylean Tragedy. London: Duckworth.

Swift, L. A. (2010). The Hidden Chorus. Echoes of Genre in Tragic Lyric. Oxford: Oxford Univ. Press.

Taplin, O. (1972). Aeschylean Silences and Silences in Aeschylus. HSCPh 76, 57-97.

Taplin, O. (1977). The Stagecraft of Aeschylus. Oxford: Oxford University Press.

West, M. L. (1990). Studies in Aeschylus. Stuttgart: B. G. Teubner.

Wilamowitz, U von. (1914). Aeschyli Tragoediae. Berolini: Weidmann.

Wright, M. (2019). The Lost Plays of Greek Tragedy. Volume 2. London: Bloomsbury Academic.

\section{Notas}

1 Por consideraciones de espacio, no identificaré todos los detalles del argumento de cada drama. Sólo se tendrán en cuenta los elementos que sean pertinentes para identificar al coro o analizar su función dramática. El orden en el que presento los dramas en los siguientes apartados es el seguido por Radt, 1985, pp. 111-119. El detalle de las distintas propuestas sobre el argumento de las tragedias mencionadas se puede consultar en Lucas de Dios (2008), Sommerstein (2008) y Wright (2019), a quienes remito.

2 Las Musas habían participado también en el lamento fúnebre por Memnón (Proclo, Crestomatía 198-199 Seve.) y Aquiles (Odisea 24.60-62). Sobre la influencia de estos pasajes épicos en la tragedia véase Liapis, 2012, p. xxiii. Jouan, 1992, p. 75, por su parte, piensa en una sola musa ex machina, que traería en sus manos la cabeza de Orfeo.

3 Omitiré los fragmentos de dramas satíricos, al estar el coro en ese caso conformado necesariamente por sátiros.

4 Sobre las distintas posibilidades y el orden de los dramas dentro de la tetralogía véase Garvie, 2006, pp. 163-233; Radt, 1985 , p. 112.

5 Sobre la posición y papel de los coros suplementarios en la tragedia véase Taplin, 1977, pp. 235-237.

6 El doble sentido depende de la intepretación de $\pi \rho \varepsilon \nu \mu \varepsilon \nu \eta \dot{s, ~ q u e ~ p u e d e ~ s i g n i f i c a r ~ " a m a b l e, ~ b e n e ́ v o l o " ~(L S J ~ A), ~ r e f e r i d o ~ a ~}$ una persona, pero también “propicio” (LSJ B), referido a un fallecido. Véase Garvie, 2009, pp. 129, 254.

7 Sobre la composición y el orden de la tetralogía sobre Prometeo véase e.g. Radt, 1985, pp. 112-113; Taplin, 1977, pp. 460-469; Sommerstein, 20102 , pp. 224-228.

8 Sobre la composición de la tetralogía véase Radt, 1985, p. 113. 
9 Sobre la composición y el orden de los dramas dentro de esta tetralogía véase Radt, 1985, pp. 113-114.

10 Sobre el orden de los dramas que componían esta tetralogía véase Radt, 1985, p. 114.

11 Compárese con el pasaje de Ferécides (7 b 2 D.-K.) en el que se describe cómo Zeus (Zas) entrega a su novia la Tierra un

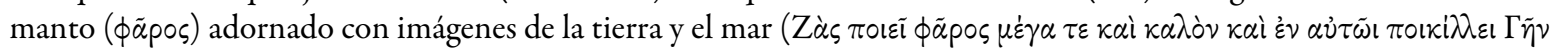

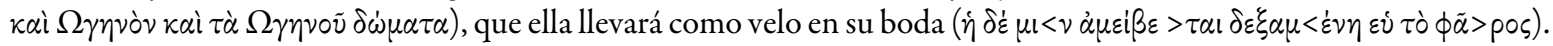

12 Sobre los dramas que podrían formar parte de esta tetralogía véase Radt, 1985, p. 114. Sobre Frigios ( pújıı) véase el apartado 3.12 .

13 Sobre la composición y el orden de los dramas en esta tetralogía véase Radt, 1985, p. 116.

14 Sobre los dramas de regreso (nostos play) véase Taplin, 1977, pp. 124-125, 302.

15 Otros consideran que la tragedia dramatizaba el castigo de las hijas de Minias, rey de Orcómenos, por no aceptar el culto dionisíaco (Smyth, 1957, pp. 435-436; Jouan, 1992, pp. 77-78).

16 Sobre la composición y el orden de esta tetralogía véase Radt, 1985, p. 118.

17 No está claro, aun así, por qué un grupo de jóvenes tebanas tendría aspecto de amazonas. El fragmento podría referirse a una descripción de Ártemis (cf. Lucas de Dios, 2008, p. 480 n. 1497) o a la joven que pronuncia el fr. 157a R. (Mette, 1963, p. 46). Por otro lado, el coro podría estar formado por jóvenes lidias, compatriotas de Níobe, que la hubieran acompañado hasta Tebas por su matrimonio (cf. Lucas de Dios, 2008, p. 475). Aunque no es ciertamente lo habitual que un coro compuesto por personajes femeninos se aleje de su lugar de nacimiento, al menos dos coros femeninos declaran haber viajado desde su patria al lugar donde se representa el drama: las mujeres fenicias de Eurípides, Fenicias 202-214 y de Frínico 3 fr. 9 Sn.-K.

18 Véase las posibilidades en Radt, 1985, p. 119.

19 Sobre la composición de esta posible tetralogía véase Radt, 1985, p. 118.

20 Consúltese la cifra y los títulos en Radt (1985) y Lucas de Dios (2008).

21 Es evidente que los títulos que han llegado hasta nuestros días no se corresponden necesariamente con las denominaciones originales de los dramas de Esquilo (Taplin, 1977, p. 164 n.), pero, como mínimo, sí son testimonio de que, al menos para los filólogos alejandrinos, los títulos señalarían alguna característica distintiva del drama, tal y como la identidad de su coro, su personaje principal, o la situación dramática. 